Pedro E.G. Loureiro*, Joana I.T. Sousa, M. Graça. V.S. Carvalho and Dmitry V. Evtuguin

\title{
Contribution of xylan to the brightness development and stability in the final ECF bleaching of eucalypt (Eucalyptus globulus Labill.) kraft pulp
}

\begin{abstract}
Xylans isolated from eucalypt kraft pulps have been characterized by modern analytical methods. The pulps were partially bleached $\left(\mathrm{DE}_{\mathrm{OP}} \mathrm{D}\right)$ and fully bleached with either a final $\mathrm{ClO}_{2}\left(\mathrm{DE}_{\mathrm{OP}} \mathrm{DD}\right)$ or an alkaline $\mathrm{H}_{2} \mathrm{O}_{2}$ $\left(\mathrm{DE}_{\mathrm{OP}} \mathrm{DP}\right)$ bleaching stage. Alternatively, xylan isolated from the $\mathrm{DE}_{\mathrm{OP}} \mathrm{D}$ pulp was treated with $\mathrm{ClO}_{2}$ or with $\mathrm{H}_{2} \mathrm{O}_{2}$ under the same conditions as pulps in a final bleaching stage and were further characterized. ${ }^{1} \mathrm{H}$ nuclear magnetic resonance, size exclusion chromatography, UV-vis spectroscopy in cadoxen solution, and UV-resonance Raman spectroscopy were applied as analytical methods. The final $\mathrm{ClO}_{2}$ stage generated new unsaturated moieties in xylan, whereas $\mathrm{H}_{2} \mathrm{O}_{2}$ was very effective in the removal of xylan-related chromophores. The role of xylan to the delay of brightness development in the final $\mathrm{ClO}_{2}$ stage was highlighted by means of a pretreatment with xylanase Pulpzyme HC before the final bleaching stage. By this approach, the final bleachability of the pulp was boosted and the brightness stability of the fully bleached pulp was improved.
\end{abstract}

Keywords: bleaching sequences, brightness, chlorine dioxide, Eucalyptus globulus, final bleaching, hydrogen peroxide, pulp, xylan, xylanase

*Corresponding author: Pedro E.G. Loureiro, Novozymes A/S, Brudelysvej, 32 DK-2880 Bagsværd, Denmark,

e-mail: peul@novozymes.com

Pedro E.G. Loureiro and Dmitry V. Evtuguin: CICECO, Department of Chemistry, University of Aveiro, 3810-193 Aveiro, Portugal Joana I.T. Sousa and M. Graça. V.S. Carvalho: CIEPQPF, Department of Chemical Engineering, University of Coimbra, 3030-790 Coimbra, Portugal

\section{Introduction}

The final stages of the bleaching chemistry of pulps are poorly investigated mainly because of the difficult assessment of the remaining chromophores (Mateo et al. 2001;
Rosenau et al. 2007). Therefore, it is difficult to develop a defined strategy for the removal of the residual chromophores; brightness development and stability are still insufficient in the final stages of bleaching (Loureiro et al. 2011, 2012).

The brightness gain and reversion are especially dependent from cellulose and hemicelluloses, because these carbohydrates are vulnerable to oxidation in the presence of bleaching reagents. With respect to eucalypt fibers, xylan is its most abundant hemicellulose component with the highest accessibility toward bleaching agents. This is one of the reasons why hemicelluloses also as parts of lignin carbohydrate complexes (LCCs, including xylan) - of eucalypt (mainly Eucalyptus globulus Labill.) were studied in recent years (Mendes et al. 2009; Al-Dajani and Tschirner 2010; dos Santos et al. 2011; Li et al. 2011; Zhou et al. 2011; Rodríguez-López et al. 2012; Vila et al. 2013). Focusing on xylan in the final bleaching stages would probably provide new insights to the optimization of the process. Xylan contains carboxyl groups, including both the native uronic acids and the hexeneuronic acids (HexA) produced during kraft cooking (Buchert et al. 1997). HexA has been previously identified as an important contributor to the brightness reversion of bleached pulps (Vuorinen et al. 1999; Sevastyanova et al. 2006). However, in elemental chlorine-free (ECF) bleaching based on $\mathrm{ClO}_{2}$, solely the content of residual HexA in bleached pulps does not explain the differences in their brightness reversion (Süss et al. 2004; Eiras and Colodette 2005; Loureiro et al. 2012).

The xylan-lignin complex was shown to be a source of residual polyconjugated chromophores in highly bleached eucalypt pulps (Loureiro et al. 2010). Its importance in aging reactions was highlighted by comparing a final $D$ to a final P stage in the ECF bleaching of eucalypt kraft pulp (Loureiro et al. 2012). Previous studies have also revealed the advantage of a final xylanase treatment to improve the pulp brightness stability (Buchert et al. 1997; DeLozier et al. 2004; Simeonova et al. 2007; Valchev and Tsekova 2010). 
There are conspicuous differences in brightness gain and reversion between $\mathrm{DE}_{\mathrm{OP}} \mathrm{DD}$ and $\mathrm{DE}_{\mathrm{OP}} \mathrm{DP}$ bleached eucalypt pulps, which are independent of their HexA content (Loureiro et al. 2010). This is the reason why these pulps were selected in the present study. Xylans were isolated from partially bleached $\left(\mathrm{DE}_{\mathrm{OP}} \mathrm{D}\right)$ and fully bleached $\left(\mathrm{DE}_{\mathrm{OP}} \mathrm{DD}\right.$ vs. $\mathrm{DE} \mathrm{OP}_{\mathrm{PP}} \mathrm{DP}$ ) eucalypt kraft pulps and characterized employing ${ }^{1} \mathrm{H}$ nuclear magnetic resonance (NMR) and UV-vis spectroscopy in cadoxen solution and size exclusion chromatography (SEC) in combination with solid-state UV-resonance Raman (UV-RR) spectroscopy. In addition, a comparative analysis was done on the xylan isolated from the partially bleached pulp $\left(\mathrm{DE}_{\mathrm{OP}} \mathrm{D}\right)$, which was subjected to treatments with either $\mathrm{ClO}_{2}$ or alkaline $\mathrm{H}_{2} \mathrm{O}_{2}$ in a similar fashion as in the final bleaching stages. Finally, the brightness gain and stability of the fully bleached pulp was assessed after the introduction of a xylanase treatment (X-stage) in combination with a final D or P stage.

\section{Materials and methods}

\section{Xylans, pulps, xylanase treatment, and brightness measurements}

In a previous study (Loureiro et al. 2010), $\mathrm{DE}_{\mathrm{OP}} \mathrm{D}, \mathrm{DE}_{\mathrm{OP}} \mathrm{DD}$, and $\mathrm{DE} \mathrm{OP}_{\mathrm{P}} \mathrm{DP}$ bleached pulps were characterized and the xylan from each of these pulps was isolated. In that study, excessive dosage of $\mathrm{ClO}_{2}$ or $\mathrm{H}_{2} \mathrm{O}_{2}$ up to $8.0 \%$ oven dry pulp (odp) was used in the final D or P stages to induce significant structural changes. In this study, those previously isolated xylans are further characterized. In addition, the xylan isolated from the $\mathrm{DE}_{\mathrm{OP}} \mathrm{D}$ pulp (for simplicity, $\mathrm{DED}$ ) served as a modelxylan, which was subjected to treatment with either $\mathrm{ClO}_{2}$ or $\mathrm{H}_{2} \mathrm{O}_{2}$ in excessive amounts.

To evaluate the combination of a xylanase stage in the final bleaching, the same industrially $\mathrm{DE}_{\mathrm{OP}} \mathrm{D}$ bleached kraft pulp produced from E. globulus wood was used in this study, which was supplied by a Portuguese pulp mill (grupo Portucel Soporcel). This pulp was washed in the laboratory with distilled water and kept in the fridge at $4^{\circ} \mathrm{C}$. All trials were run at $10 \%$ consistency in sealed polyethylene bags immersed in a temperature-controlled water bath. This pulp was bleached at different stages by a combination of $\mathrm{ClO}_{2}, \mathrm{H}_{2} \mathrm{O}_{2}$, and xylanase. The standard bleaching conditions were applied to reach the target of 90-91\% ISO brightness. D-stage: dosage of chemicals of $0.15-0.35 \%$ odp $\mathrm{ClO}_{2}$ (as active $\mathrm{Cl}_{2}$ ) at $70^{\circ} \mathrm{C}$ for $150 \mathrm{~min}$. P-stage: dosage of chemicals of $0.5-0.7 \%$ odp $\mathrm{H}_{2} \mathrm{O}_{2}, 0.65 \%$ odp $\mathrm{NaOH}$, and $0.2 \%$ odp $\mathrm{MgSO}_{4} \cdot 7 \mathrm{H}_{2} \mathrm{O}$ at $70^{\circ} \mathrm{C}$ for $60 \mathrm{~min}$. X-stage: The xylanase Pulpzyme HC was supplied by Novozymes A/S; activity: 1000 AXU g-1 according to the supplier. The dosage of xylanase was $0.05 \%$ odp Pulpzyme $\mathrm{HC}$ at $\mathrm{pH} 8$ at $60^{\circ} \mathrm{C}$ for $2 \mathrm{~h}$. Pulp brightness: The handsheets were made according to ISO 3688. The measurement of the diffuse blue reflectance factor (ISO brightness) was according to ISO 2470. The brightness reversion tests were performed according to TAPPI T 260: wet thermal reversion was determined at $100^{\circ} \mathrm{C}$ and $100 \%$ relative humidity.

\section{Xylan bleaching}

DED xylan (50 mg) previously isolated from the $\mathrm{DE}_{\mathrm{OP}} \mathrm{D}$ pulp was dissolved in distilled water at room temperature for 3 days under stirring. The dissolved xylan was then bleached with $10 \% \mathrm{ClO}_{2}$ (dry xylan basis, as active $\left.\mathrm{Cl}_{2}\right)$ at $0.5 \%$ consistency under stirring $\left(70^{\circ} \mathrm{C}\right)$ in a glass screw-top tube during $1 \mathrm{~h}$ (an initial pH of 3.6). As for $\mathrm{H}_{2} \mathrm{O}_{2}$ bleaching, xylan was dissolved for $1 \mathrm{~h}$ at room temperature with distilled water previously set to $\mathrm{pH} 11.9$ with the addition of $\mathrm{NaOH}$ under stirring. Then, $10 \% \mathrm{H}_{2} \mathrm{O}_{2}$ (dry xylan basis) was added at $0.5 \%$ consistency and for $1 \mathrm{~h}$ at $90^{\circ} \mathrm{C}$. After bleaching, the produced DED-D and DED-P bleached xylans were precipitated in MeOH-EtOH solution and consecutively and repeatedly centrifuged and washed with $\mathrm{MeOH}$ and finally dried in vacuum in room temperature. The same purification procedure was applied for the isolated xylans.

\section{Analysis of xylans}

UV-vis spectroscopy: $3 \mathrm{mg}$ xylan was dissolved in $15 \mathrm{ml}$ cadoxen under stirring. The solutions were then diluted with $15 \mathrm{ml}$ water and the UV-vis spectra were recorded on a JASCO V-560 spectrophotometer. The scanning speed was $200 \mathrm{~nm} \mathrm{~min}{ }^{-1}$ and the bandwidth was $2 \mathrm{~nm}$; the blank reference was cadoxen-water solution (1:1).

${ }^{1} \mathrm{H}$ NMR spectroscopy: The xylans were dissolved in $\mathrm{D}_{2} \mathrm{O}$ and in the presence of sodium 3-(trimethylsilyl)-propionate- $\mathrm{d}_{4}$ as an internal standard. The ${ }^{1} \mathrm{H}$ NMR spectra were recorded at room temperature on a Bruker AMX 300 spectrometer operating at $300.1 \mathrm{MHz}$. Parameter: relaxation delay of $12 \mathrm{~s}$, r.f. angle of $90^{\circ}, 500$ scans.

Molecular weight distribution by SEC: Instrument: PLGPC 110 system (Polymer Laboratories, UK); Columns: two PLgel $10 \mu \mathrm{m}$ Mixed B $300 \times 7.5 \mathrm{~mm}$ columns with a PLgel $10 \mu \mathrm{m}$ pre-column (Polymer Laboratories). Temperature of the columns, injector system, and the detector (RI): $70^{\circ} \mathrm{C}$. Then, $3-4 \mathrm{mg}$ xylan was dissolved in $100 \mu \mathrm{l}$ of $8 \% \mathrm{LiCl} / \mathrm{N}, \mathrm{N}$-dimethylacetamide (DMAc) solution at $105^{\circ} \mathrm{C}$ for $1 \mathrm{~h}$ and then further diluted with $600 \mu \mathrm{l}$ DMAc. Eluent: $0.1 \mathrm{M} \mathrm{LiCl}$ in DMAc, $0.9 \mathrm{ml} \mathrm{min}{ }^{-1}$. The analytical columns were calibrated with Pullulan standards (Polymer Laboratories).

UV-RR spectroscopy: Instrument: Jobin Yvon (Horiba) LabRam HR 800 micro-Raman spectrometer at 325 nm (He-Cd UV laser, Kimmon IK Series) under back-scattering configuration equipped with a $\times 40$ NUV objective. To avoid sample photodegradation, a neutral density filter (ND 0.6) was used for the spectral acquisition of the xylan samples. Spectral range: $750-1800 \mathrm{~cm}^{-1}$; each sample was analyzed at least at three points to obtain an average spectrum. The spectral data were subjected to background correction (linear luminescence-fluorescence) and normalized to the $1375 \mathrm{~cm}^{-1}$ band. For the quantitative analysis, curve fitting was made based on Lorentzian peak functions without smoothing the normalized spectra.

\section{Results and discussion}

\section{${ }^{1} \mathrm{H}$ NMR, UV-vis spectroscopy, and SEC}

The ${ }^{1} \mathrm{H}$ NMR spectra of xylans isolated from $\mathrm{DE}_{\mathrm{OP}} \mathrm{D}$, $\mathrm{DE}_{\mathrm{OP}} \mathrm{DD}$, and $\mathrm{DE}_{\mathrm{OP}} \mathrm{DP}$ bleached pulps did not show 
detectable signals at $6.0-8.0 \mathrm{ppm}$, which are typical for aromatic protons in residual lignin (Figure 1). At the same time, absorption at $280 \mathrm{~nm}$ in the UV spectra of all xylans dissolved in cadoxen was registered (Figure 2).

The UV absorption at this region is abnormal for pure polysaccharides (Evtuguin et al. 2002) and indicates the presence of aromatic structures or other compounds with highly conjugated double-bond systems. In addition, some new unsaturated structures different than HexA appeared at $240-260 \mathrm{~nm}$ in the UV-vis spectra of xylans dissolved in cadoxen (Figure 2). In fact, the ${ }^{1} \mathrm{H}$ NMR spectra showed that DED and DEDP xylans exhibited notable signals at 8.37 and $8.44 \mathrm{ppm}$, respectively, assigned to unknown unsaturated structures (Figure 1). Similar features were observed previously with birch xylan enriched in HexA and treated with $\mathrm{O}_{3}$ and $\mathrm{ClO}_{2}$ (Domingues and Evtuguin 2001).

Based on the molecular weight of xylans extracted from the pulps and the DED model-xylan treated with D and P stages (Table 1), it can be concluded that the harsh

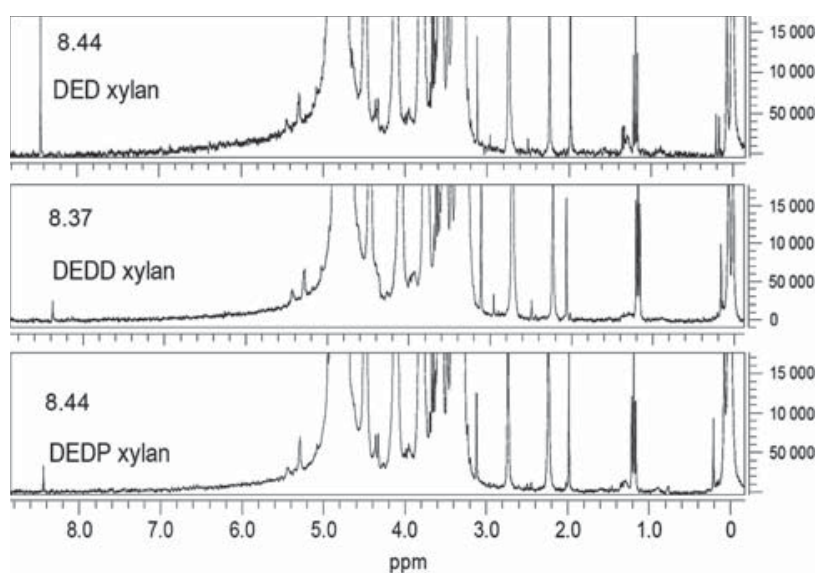

Figure $1{ }^{1} \mathrm{H}$ NMR spectra of the isolated xylans.

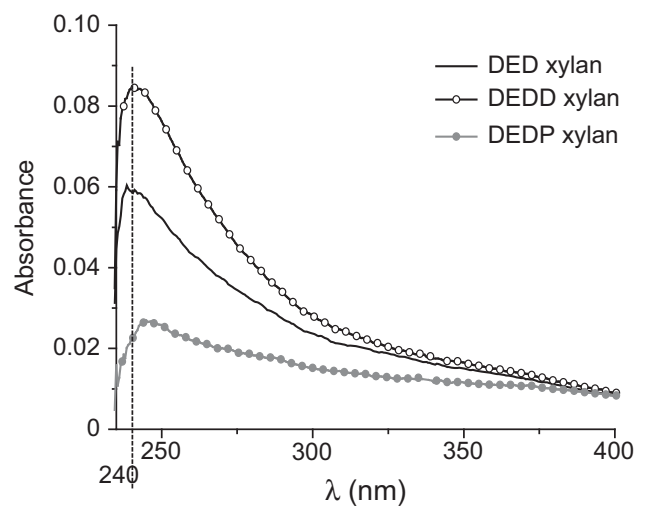

Figure 2 UV-vis spectra of the isolated xylans dissolved in cadoxen.
Table 1 Weight average molecular weight (Mw), number average molecular weight $(\mathrm{Mn})$, and polydispersity $(\mathrm{PD})$ values of the isolated and bleached xylans from SEC analysis.

\begin{tabular}{lrrr}
\hline Xylan code & $\mathbf{M}_{\mathbf{w}}(\mathbf{k D a})$ & $\mathbf{M}_{\mathbf{n}}(\mathbf{k D a})$ & $\mathbf{P D}$ \\
\hline Isolated DED & 14.8 & 9.2 & 1.62 \\
Isolated DEDD & 13.2 & 8.6 & 1.54 \\
Isolated DEDP & 12.9 & 7.9 & 1.64 \\
Bleached DED-D & 14.4 & 8.7 & 1.65 \\
Bleached DED-P & 12.0 & 6.9 & 1.73 \\
\hline
\end{tabular}

final bleaching treatment induced more xylan degradation with $\mathrm{H}_{2} \mathrm{O}_{2}$ than with $\mathrm{ClO}_{2}$. In general, the tendencies in degradation of xylan in DED pulp and xylan isolated from DED pulp as a model sample were similar after the treatments in D and P stages. Some more degradation of model xylan was observed than that obtained with the retained xylan in DED pulp after the P stage (bleached DED-P vs. DEDP xylans; Figure 3), which may be explained by better accessibility of the former. Additionally, the oxidized xylan in pulp may undergo some structural association with cellulose. This process is similar to that observed during crosslinking of oxidized cellulose, the solubility of which is decreased in typical cellulose solvents (Potthast et al. 2005).

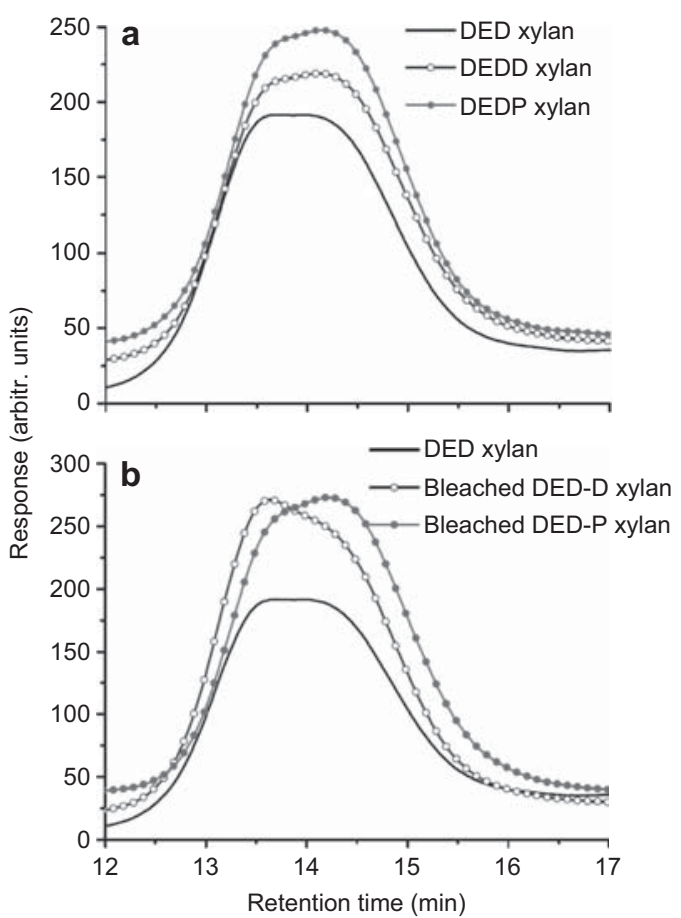

Figure 3 SEC curves (offset) of (a) the xylans isolated from DED, DEDD, and DEDP bleached pulps and (b) the DED xylan before and after bleaching with $\mathrm{ClO}_{2}$ (DED-D) and $\mathrm{H}_{2} \mathrm{O}_{2}$ (DED-P). 


\section{UV-RR spectroscopy}

UV-RR spectroscopy is the method of choice for detecting the aromatic bands of residual lignin in pulps (Halttunen et al. 2001; Jääskeläinen et al. 2009). Loureiro et al. (2010, 2011) showed by UV-RR coupled to UV-vis diffuse reflectance (DR) spectroscopy that xylan is an important source of chromophores in bleached eucalypt pulps. A particular selectivity in the detection and identification of chromophores in pulps is achieved with UV-RR at $325 \mathrm{~nm}$ laser beam excitation. This band at $325 \mathrm{~nm}$ in the DR spectra corresponds to the absorption of polyunsaturated chromophore structures (Loureiro et al. 2011).

The UV-RR spectra of the xylan isolated from the DED bleached pulp and posttreated with $\mathrm{ClO}_{2}$ and $\mathrm{H}_{2} \mathrm{O}_{2}$ are presented in Figure 4. It was observed that alkaline $\mathrm{H}_{2} \mathrm{O}_{2}$ treatment has reduced the amount of polyconjugated chromophore structures detected at $\sim 1600 \mathrm{~cm}^{-1}$. As far as the acidic $\mathrm{ClO}_{2}$ treatment is concerned, the amount of chromophores did not change. In addition, it can be concluded that the nature of chromophores in xylan is different in relation to the particular final bleaching stage (Figure 4; Table 2).

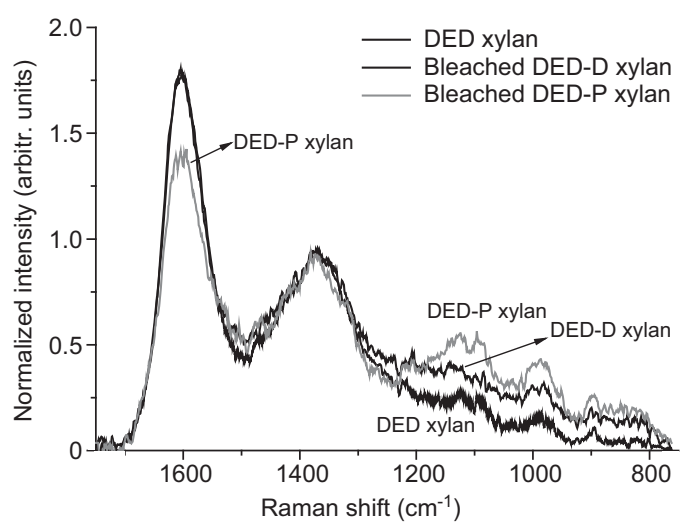

Figure 4 UV-RR spectra of the DED model-xylan before and after bleaching with $\mathrm{ClO}_{2}$ (DED-D) and $\mathrm{H}_{2} \mathrm{O}_{2}$ (DED-P). DED-xylan and bleached DED-D xylan are nearly identical over the $1300-1700 \mathrm{~cm}^{-1}$ range.

Table 2 Characteristic Raman signals of xylan-related chromophores: model-xylan (DED) before and after bleaching with $\mathrm{ClO}_{2}$ (DED-D) and $\mathrm{H}_{2} \mathrm{O}_{2}$ (DED-P).

\begin{tabular}{lrrrr}
\hline Xylan code & \multicolumn{3}{c}{ Chromophore signals $\left(\mathbf{c m}^{-1}\right)$} \\
\cline { 2 - 5 } & Maximum & & \multicolumn{2}{c}{ Band deconvolution } \\
\hline DED & 1601 & 1623 & 1600 & 1573 \\
DED-D & 1604 & 1627 & 1605 & 1578 \\
DED-P & 1594 & 1621 & 1591 & 1540 \\
\hline
\end{tabular}

The characteristic signals of chromophores belonging to the DED xylan bleached with alkaline $\mathrm{H}_{2} \mathrm{O}_{2}$ are downshifted compared with the original xylan. Conversely, the signals from chromophores of DED xylan bleached with $\mathrm{ClO}_{2}$ are up-shifted. The signal at $\sim 1627 \mathrm{~cm}^{-1}$ (Table 2) is typical for a more extended chromophoric system, such as the conjugated units bearing aromatic, ethylenic, and carboxylic acid groups (Agarwal et al. 2005; Loureiro et al. 2011) present in the DED-D xylan. This is in agreement with the results of Loureiro et al. (2010) concerning extracted xylans from fully bleached pulps, where the final $\mathrm{ClO}_{2}$ treatment increased the amount of conjugated structures in xylan. However, in the quoted study, this effect was more noticeable on the increased intensity of the Raman signal at $\sim 1600 \mathrm{~cm}^{-1}$ of the xylan isolated from the DEDD bleached pulp. This difference in chromophores between xylan oxidized in the pulp bulk and in solution can be explained, at least partially, by the incomplete dissolution of oxidized xylan fragments extracted from bulk in solution during bleaching. An increased dosage of $\mathrm{ClO}_{2}$ could have compensated the difficult accessibility of the reactive chlorine species and rendered more noticeable differences.

In contrast to the treatment with $\mathrm{ClO}_{2}$, the removal of chromophores from xylan bleached with $\mathrm{H}_{2} \mathrm{O}_{2}$ is easier. The hydroperoxy anion ( $\mathrm{HOO}^{-}$) is considered as the primary brightening agent in alkaline $\mathrm{H}_{2} \mathrm{O}_{2}$ bleaching. The nucleophilic addition of the hydroperoxy anion into the conjugated carbonyl structures and quinoid structures are well-documented reactions (Gierer 1985; Schwanninger 2006; Pipon et al. 2007) and thus could partly explain the decrease in the polyconjugated xylan-related chromophores. Lachenal et al. (2012) also emphasized the detrimental effects of quinone formation during $\mathrm{ClO}_{2}$ bleaching and recommended a subsequent $\mathrm{H}_{2} \mathrm{O}_{2}$ step for brightness improvement. However, the amount of chromogen and chromophore structures in pulp is not only the result of a direct oxidative degradation of the reactive species but also the consequence of their degree of extraction/leaching, which is favored under the alkaline conditions of the final P stage.

Although the peroxide-treated xylan had a lower amount or residual chromophores, this xylan showed an increased oxidation degree as revealed by increased bands at 1120 and $1093 \mathrm{~cm}^{-1}$ in the UV-RR spectra (Figure 4) coresponsible to O-C-O vibrations in hydrated carbonyls (Loureiro et al. 2010). This fact is reflected by more extended xylan degradation (leading to lower Mw and $\mathrm{Mn}$ ) in the final P stage compared with the D stage (Table 1).

In terms of furan-type chromogen structures detectable at $-1480 \mathrm{~cm}^{-1}$ in the UV-RR spectra, this signal was 
more noticeable after the final bleaching. This may also explain why xylan chromophores are more difficult to remove on $\mathrm{ClO}_{2}$ bleaching; thus, this pulp suffers high brightness reversion due to the conversion of chromogens into chromophores.

\section{Effect of a xylanase stage (X)}

The observed contribution of xylan to the brightness development and stability in the final ECF bleaching, especially in case of $\mathrm{ClO}_{2}$, was the impetus for studying the effect of a xylanase treatment either before or after the $\mathrm{D}_{2}$ or P stage in terms of brightness gain and stability of the fully bleached pulp. The same dosage of enzyme was used in all experiments as shown in Figure $5 . \mathrm{H}_{2} \mathrm{O}_{2}$ and $\mathrm{ClO}_{2}$ charges were the same before and after the X treatment. This charge was adapted to reach similar brightnesses as obtained for $\mathrm{D}$ and $\mathrm{P}$ pulps (without enzyme treatment).

As visible in Figure 5, the xylanase treatment $\left(\mathrm{DE}_{\mathrm{OP}} \mathrm{DX}\right)$ is itself able to lead to 1.5-2.0 ISO brightness gains in agreement with previous findings (Valchev and Tsekova 2010). This finding proves also the role of xylan as a source of chromophores. On the contrary, the xylanase stage was more effective before the final stage (XD or XP vs. DX or $\mathrm{PX}$ ) regarding brightness gain and the reversion (in terms of PC number). The xylanase treatment decreased the brightness reversion significantly especially in combination with a final D stage (Figure 5).

The xylanase had a more pronounced effect on boosting the final $\mathrm{ClO}_{2}$ bleaching in the $\mathrm{DE}_{\mathrm{OP}} \mathrm{DXD}$ sequence. For high target brightness above $91 \%$, it was possible to save $\sim 75 \% \mathrm{ClO}_{2}$ in the $\mathrm{D}_{2}$ stage and improve

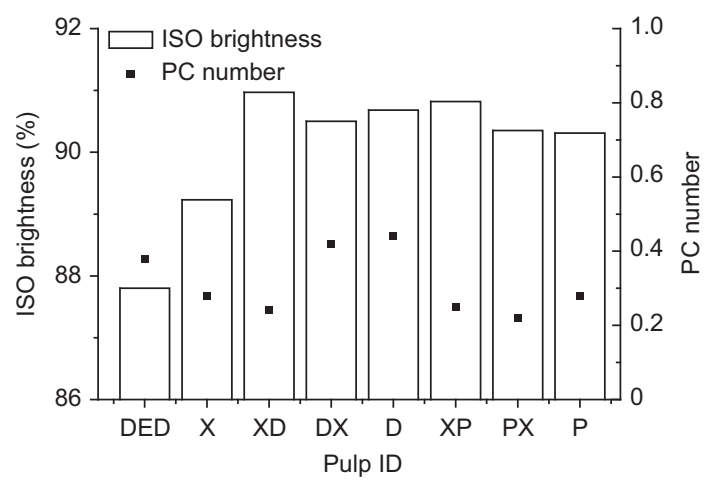

Figure 5 Effect on the brightness gain and PC number while combining a xylanase stage with $\mathrm{ClO}_{2}$ and $\mathrm{H}_{2} \mathrm{O}_{2}$ stages in the final ECF bleaching of eucalypt kraft pulp.

DED was the original pulp. significantly the brightness stability (PC number 0.27 vs. 0.40). This boosting effect is similar to the welldocumented bleach boosting application of xylanases at the beginning of the bleaching sequence (Pedersen et al. 1992; Daneault et al. 1994; Viikari et al.1994; Bajpai 1999). In that application point, it is hypothesized that the xylanase either removes reprecipitated xylan from the kraft cooking or degrades lignin carbohydrate complexes and facilitates the extractability of lignin in the following bleaching stages (Viikari et al. 1994). In the final bleaching, the hydrolytic action of the xylanase is supposed to release resistant chromophores attached to the xylan backbone and contributes in this way to the brightness gain.

These residual xylan-based chromophores are likely part of the degraded residual xylan-lignin complex, which also contains polyunsaturated structures from lignin (Loureiro et al. 2012). The latter may include either heteroaromatic compounds (Bikova et al. 2005) or regenerated aromatic chromophores (Popoff and Theander 1972; Theander and Nelson 1988) or, more specifically, hydroxyquinones structures that were identified as resistant chromophores that originated from oxidized carbohydrates (Rosenau et al. 2007). However, the exact contribution of the different chromophores to pulp brightness and bleachability is not yet clear.

Besides chromophores, the xylanase treatment removes chromogenic structures, that is, latent chromophores, which may contribute to the brightness reversion. Among xylan-derived chromogens, HexA, furan derivatives, and other oxidized compounds are likely removed from the pulp.

\section{Conclusion}

The final bleaching with $\mathrm{ClO}_{2}$ produces unsaturated moieties in xylan different from HexA residues and from those present in the original xylan isolated from a $\mathrm{DE}_{\mathrm{OP}} \mathrm{D}$ bleached pulp, which absorb at 240-260 nm. This was also noticeable by employing UV-RR spectroscopy from the increased structural conjugation of chromophores in model-xylan bleached with $\mathrm{ClO}_{2}$. Compared with $\mathrm{ClO}_{2}$, the final alkaline $\mathrm{H}_{2} \mathrm{O}_{2}$ stage is more efficient in terms of the removal of xylan-related chromophores, although it is more detrimental regarding the xylan integrity. A xylanase treatment provided further evidence to the role of xylan both as a source of chromophores and chromogen structures. The X-stage provides a positive effect on the brightness stability of fully bleached ECF pulp and, 
if applied before the final bleaching stage, allows significant savings in bleaching chemicals, especially $\mathrm{ClO}_{2}$.

Acknowledgments: The authors are grateful to the FCT (Portuguese Foundation for Science and Technology) and the UE-FEDER (European Fund for Regional Development) through the Competitiveness Factors Operational Programme (COMPETE) for the financial support of this work within the scope of Projects PTDC/EQU-EQU/113547/2009
(COMPETE, ref. FCOMP-01-0124-FEDER-015254) and POPH-QREN funding program and FCT-MCTES for the doctoral degree grant SFRH/BD/29690/2006. Grupo Portucel Soporcel is acknowledged for supplying the pulp and Novozymes A/S for supplying the xylanase product Pulpzyme HC.

Received October 31, 2012; accepted February 5, 2013; previously published online $x x$

\section{References}

\begin{tabular}{|l|}
\hline Q2: \\
Please \\
supply \\
editor name \\
for Refs. \\
“Agarwal \\
et al. 2005”, \\
"DeLozier \\
et al. 2004”, \\
"Domingues \\
and Evtu- \\
guin 2001", \\
"Pedersen \\
et al. 1992”, \\
if available \\
\hline
\end{tabular}

Agarwal, U., Reiner, R.S., Pandey, A.K., Ralph, S.A., Hirth, K.C., Atalla, R.H. (2005) Raman spectra of lignin model compounds. In: $5^{\text {th }}$ APPITA Annual Conference and Exhibition $/ 13^{\text {th }}$ International Symposium on Wood, Fibre and Pulping Chemistry, Auckland, New Zealand. pp. 1-8 (CD version).

Al-Dajani, W.W., Tschirner, U.W. (2010) Pre-extraction of hemicelluloses and subsequent ASA and ASAM pulping: comparison of autohydrolysis and alkaline extraction. Holzforschung 64:411-416.

Bajpai, P. (1999) Application of enzymes in the pulp and paper industry. Biotechnol. Prog. 15:147-157.

Bikova, T., Belkova, L., Treimanis, A. (2005) Alkali-resistant chromophores in kraft pulp xylan. J. Pulp Pap. Sci. 31:193-196.

Buchert, J., Bergnor, E., Lindblad, G., Viikari, L., Ek, M. (1997) Significance of xylan and glucomannan in the brightness reversion of kraft pulps. Tappi J. 80:165-171.

Daneault, C., Leduc, C., Valade, J.L. (1994) The use of xylanases in kraft pulp bleaching: a review. Tappi J. 77:125-131.

DeLozier, G., Bloomfield, K., Xu, H. (2004) Enzymatic control of thermo-yellowing in bleached eucalypt kraft pulp. In: 37th ABTCP International Pulp and Paper Congress \& Exhibition, São Paulo, Brazil.

Domingues, R.M., Evtuguin, D.V. (2001) Behaviour of HexA residues in xylan during different bleaching stages monitored by ${ }^{1} \mathrm{H}$ NMR, SEC/MALDI-TOF and SEC/ESI-MS. In: 11th ISWPC - International Symposium on Wood and Pulping Chemistry, Nice, France. vol. 3, pp. 383-386.

dos Santos, M., Marcelo C., Pedrazzi, C., Colodette, J.L. (2011) Xylan deposition onto eucalypt pulp fibers during oxygen delignification. Holzforschung 65:605-612.

Eiras, K.M.M., Colodette, J.L. (2005) Investigation of eucalyptus kraft pulp brightness stability. J. Pulp Pap. Sci. 31:13-18.

Evtuguin, D.V., Daniel, A.I.D., Pascoal Neto, C. (2002) Determination of hexenuronic acid and residual lignin in pulps by UV spectroscopy in cadoxen solutions. J. Pulp Pap. Sci. 28:189-192.

Gierer, J. (1985) Chemistry of delignification. Part 1: general concept and reactions during pulping. Wood Sci. Technol. 19:289-312.

Halttunen, M., Vyorykka, J., Hortling, B., Tamminen, T., Batchelder, D., Zimmermann, A., Vuorinen, T. (2001) Study of residual lignin in pulp by UV resonance Raman spectroscopy. Holzforschung 55:631-638.

Jääskeläinen, A.-S., Toikka, K., Lähdetie, A., Liitiä, T., Vuorinen, T. (2009) Reactions of aromatic structures in brightness reversion of fully-bleached eucalyptus kraft pulps. Holzforschung 63:278-281.
Lachenal, D., Delmas, D., Hamzeh, Y., Benattar, N., Chirat, C., Mortha, G. (2012) Minimizing the effect of undesirable reactions in ECF bleaching. Holzforschung 66:29-33.

Li, J., Martin-Sampedro, R., Pedrazzi, C., Gellerstedt, G. (2011) Fractionation and characterization of lignin-carbohydrate complexes (LCCs) from eucalyptus fibers. Holzforschung 65:43-50.

Loureiro, P.E.G., Fernandes, A.J.S., Carvalho, M.G.V.S., Evtuguin, D.V. (2010) The assessment of chromophores in bleached cellulosic pulps employing UV-Raman spectroscopy. Carbohydr. Res. 345:1442-1451.

Loureiro, P.E.G., Fernandes, A.J.S., Furtado, F.P., Carvalho, M.G.V.S., Evtuguin, D.V. (2011) UV-resonance Raman micro-spectroscopy to assess residual chromophores in cellulosic pulps. J. Raman Spectrosc. 42:1039-1045.

Loureiro, P.E.G., Domingues, M.R.M., Fernandes, A.J.S., Carvalho, M.G.V.S., Evtuguin, D.V. (2012) Discriminating the brightness stability of cellulosic pulp in relation to the final bleaching stage. Carbohydr. Polym. 88:726-733.

Mateo, C., Chirat, C., Ait-Quaret, R., Lachenal, D. (2001) Nature and removal of the last colored chromophores in kraft pulps. Nord. Pulp Pap. Res. J. 16:385-388.

Mendes, C.V.T., Baptista, C.M.S.G., Rocha, J.M.S., Carvalho, M.G.V.S. (2009) Prehydrolysis of Eucalyptus globulus Labill. hemicelluloses prior to pulping and fermentation of the hydrolysates with the yeast Pichia stipitis 10th EWLP, Stockholm, Sweden, August 25-28, 2008. Holzforschung 63:737-743.

Pedersen, L.S., Kihlgren, P., Nissen, A.M., Munk, N., Holm, H.C., Choma, P.P. (1992) Enzymatic bleach boosting of kraft pulp - laboratory and mill scale experiences. In: 1992 Tappi Pulping Conference, Books 1-3. Tappi Press, Atlanta. pp. 31-37.

Pipon, G., Chirat, C., Lachenal, D. (2007) Comparative effect of ozone, chlorine dioxide, and hydrogen peroxide on lignin: reactions affecting pulp colour in the final bleaching stage. Holzforschung 61:628-633.

Popoff, T., Theander, O. (1972) Formation of aromatic-compounds from carbohydrates. 1. Reaction of D-glucuronic acid, D-galacturonic acid, D-xylose, and L-arabinose in slightly acidic aqueous solution. Carbohydr. Res. 22:135-149.

Potthast, A., Rosenau, T., Kosma, P., Saariaho, A.M., Vuorinen, T. (2005) On the nature of carbonyl groups in cellulosic pulps. Cellulose 12:43-50.

Rodríguez-López, J., Romaní, A., González-Muñoz, M.J., Garrote, G., Parajó, J.C. (2012) Extracting value-added products before 
pulping: hemicellulosic ethanol from Eucalyptus globulus wood. Holzforschung 66:591-599.

Rosenau, T., Potthast, A., Kosma, P., Suess, H.U., Nimmerfroh, N. (2007) Isolation and identification of residual chromophores from aged bleached pulp samples. Holzforschung 61:656-661.

Schwanninger, M. (2006) Chemistry of hydrogen peroxide bleaching. In: Handbook of Pulp. Ed. Sixta H. Volume 1. Wiley-VCH Verlag GmbH \& Co. KGaA, Weinheim. pp. 853-860.

Sevastyanova, O., Li, J.B., Gellerstedt, G. (2006) Influence of various oxidizable structures on the brightness stability of fully bleached chemical pulps. Nord. Pulp Paper Res. J. 21:49-53.

Simeonova, G., Sjodahl, R., Ragnar, M., Lindstrom, M.E., Henriksson, G. (2007) On the effect of a xylanase post-treatment as a means of reducing the yellowing of bleached hardwood kraft pulp. Nord. Pulp Pap. Res. J. 22:172-176.

Süss, H.U., Schmidt, J., Hopf, B. (2004) ECF bleaching: improving brightness stability of kraft pulp. IPW/Papier 6:73-79.
Theander, O., Nelson, D.A. (1988) Aqueous, high temperature transformation of carbohydrates relative to utilization of biomass. Adv. Carbohydr. Chem. Biochem. 46:373-326.

Valchev, I., Tsekova, P. (2010) Xylanase post-treatment as a progress in bleaching processes. Appita J. 63:53-57.

Viikari, L., Kantelinen, A., Sundquist, J., Linko, M. (1994) Xylanases in bleaching: from an idea to the industry. FEMS Microbiol. Rev. 13:335-350.

Vila, C., Francisco, J.L., Santos, V., Parajó, J.C. (2013) Effects of hydrothermal processing on the cellulosic fraction of Eucalyptus globulus wood. Holzforschung 67:33-40.

Vuorinen, T., Fagerstrom, P., Buchert, J., Tenkanen, M., Teleman, A. (1999) Selective hydrolysis of hexenuronic acid groups and its application in ECF and TCF bleaching of kraft pulps. J. Pulp Pap. Sci. 25:155-162.

Zhou, Z., Jääskeläinen, A.-S., Adorjan, I., Potthast, A., Kosma, P., Vuorinen, T. (2011) Brightness reversion of eucalyptus kraft pulp: effect of carbonyl groups generated by hypochlorous acid oxidation. Holzforschung 65:289-294. 